\title{
1. Models in research and education, planning and practice
}

\author{
F.W.T. PENNING DE VRIES ${ }^{1}$ and R. RABBINGE ${ }^{2}$ \\ ${ }^{1}$ C.T. De Wit Graduate School Production Ecology and DLO-Research Institute for Agrobiology \\ and Soil Fertility, Wageningen \\ ${ }^{2}$ C.T. De Wit Graduate School Production Ecology and Department of Theoretical Production \\ Ecology, Agricultural University, Wageningen
}

\begin{abstract}
Models are tools in which knowledge about agricultural systems is integrated. The process of model building and the application of completed models are important. The models are used for the analysis of agricultural, biological and ecological systems, for prediction of future developments and for exploration of possible behaviour of such systems.

Phases of development of explanatory models are distinguished: preliminary models, comprehensive, summary models. The values of these phases for practical applications, for education and for science are markedly different. Models for exploration and prediction are different in nature than those for disciplinary research and analysis.

modelling has gained wide acceptance as a tool in research. It is also used education programs, and is a widely accepted instrument for policy making. Examples are given of models in research (for priority setting, development of science), in education, and of use for explorative studies (such as quantitative land evaluation).

While development of crop simulation models per se continues, their association with other quantitative techniques is already emerging. There is much potential for the combined use of models with Geographic Information Systems (GIS) and Linear Programming (LP) techniques for strategic planning, but current limitations of these tools are generally underplayed. User-friendly 'shells' are beginning to bring a wealth of possibilities for simulation and for analysis to many users. The number of applications could therefore grow exponentially.

As bottlenecks for applying models at a wide scale are recognised: scarcity of basic data, lack of data for evaluation of the models, hardware, and the number of trained scientists. Which of these factors limits progress most differs among countries. Scarcity of basic data and lack of trained staff often count most, particularly in developing countries.
\end{abstract}

\section{Introduction}

Building models is a way to integrate knowledge and to make it available for various purposes. Both process and product are important because they

- help to define and categorise the state of knowledge of the subject;

- help to set priorities for research, by helping to locate gaps in knowledge and to link scientists across disciplines, levels of aggregation and from fundamental and applied sciences;

- provide a means for disseminating knowledge;

- provide a tool to make integrated knowledge operational for policy making and for resource management. 


\section{F.W.T. Penning de Vries and R. Rabbinge}

This introductory paper recalls briefly relevant definitions and concepts, and categorises models in relation to their uses. In this way, it provides a framework for the following chapters.

It is no coincidence that the various subjects in this volume are regarded from the experimental and also from the modelling side. Modelling has gained wide acceptance as a tool in research. It is also no longer restricted to the research environment, but has entered education programs, and is an instrument for policy makers. We will give some typical examples of use of models in research for priority setting and for development of scientific knowledge, of models in education, and of models used for quantitative land evaluation.

Finally, we address briefly new opportunities for linking crop models with Geographic Information Systems (GIS), Linear Programming (LP) and remote sensing (RS). Limitations for wide scale application of models are discussed, among which are prominent the lack of basic data and the shortage of scientists that are familiar with modelling approach and with uses of the available tools.

\section{Concepts in Modelling}

\section{Systems}

'One way of considering the real world is to divide it into systems. A functional description of a system is: a part of reality with strongly interacting elements, but with little influence on its environment. What part of the real world is singled out as a system depends first of all upon objectives. However, some elements of a system interact more than others, co-determining the shape of a system. Upon delimiting a system, one should thus take into account such natural contours, and consider all essential parts.' (Penning de Vries 1983). The boundaries of a system can move to expand or shrink the system under investigation in relation to the objective of the study. Ideally, boundaries are chosen such that the environment influences processes of the system, but the system itself does not influence its environment.

A theoretical delimitation of crop systems of growing crops was proposed by De Wit (De Wit and Penning de Vries 1982). He distinguished four levels of production, and corresponding systems (for their relational diagrams, see Penning de Vries et al. 1989):

- Production level 1: growth in conditions with ample soil water and nutrients. The crop growth rate is limited by weather conditions and amounts to 100$350 \mathrm{~kg} \mathrm{ha}{ }^{-1} \mathrm{~d}^{-1}$. This situation is sometimes approached on the best farms and in glasshouses.

- Production level 2: growth is limited by shortage of water for part of the growing season. This occurs on well fertilized soils in semi-arid regions and in temperate climates, but is not common in natural ecosystems.

- Production level 3: production is limited by shortage of nutrients and 


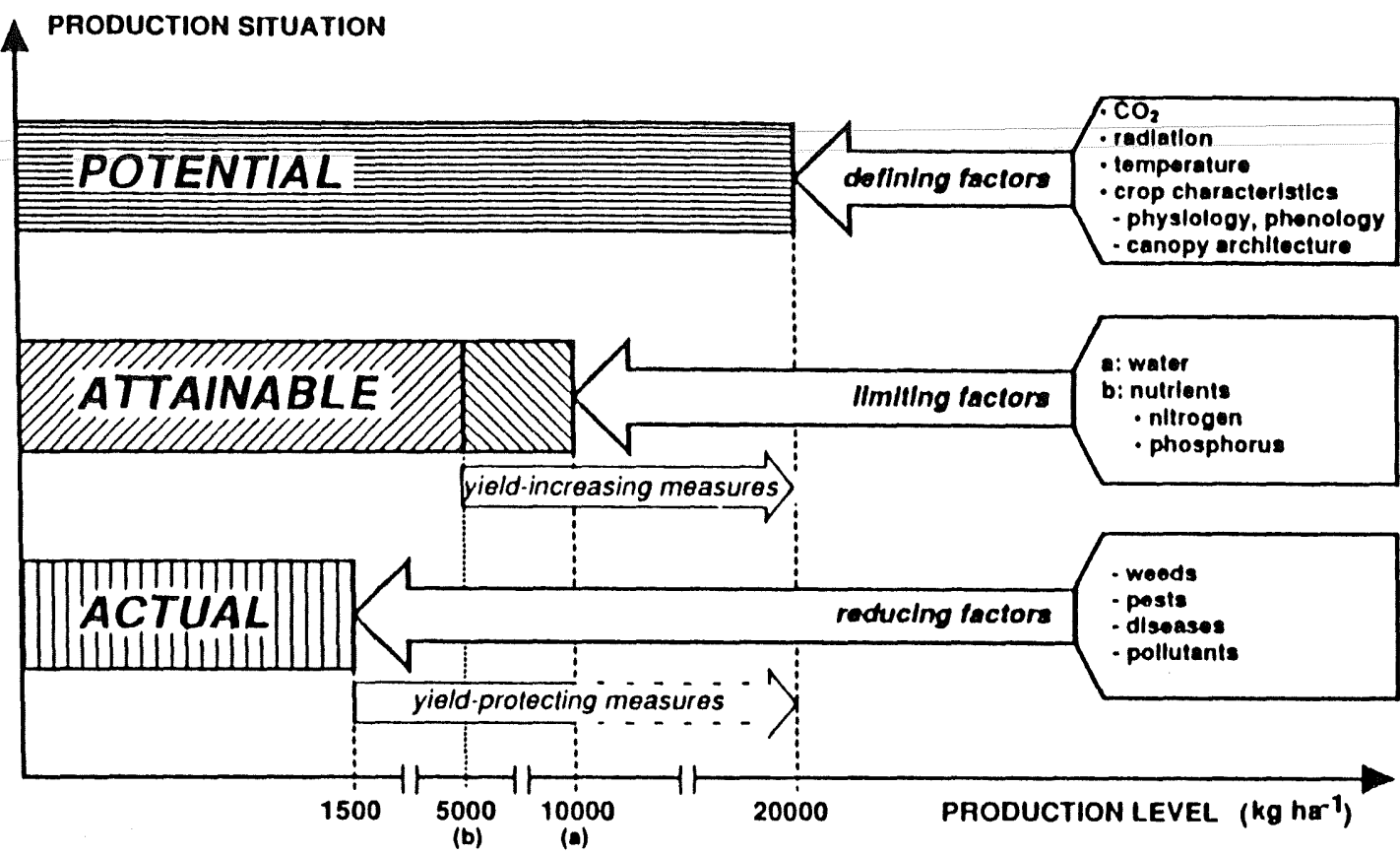

Figure 1. The relationship among potential:, attainable and actual yield and growth defining:, growth limiting and growth reducting factors (Rabbinge 1993).

sometimes by water. This is a common situation in agricultural systems using little fertilizer and in natuiral ecosystems.

- Production level 4: production is limited by availability of phospohorus or other minerals. Growth rates are $10-50 \mathrm{~kg} \mathrm{ha}^{-1} \mathrm{~d}^{-1}$ during a short growing season. This situation occurs in heavily exploited areas where no fertilizer is used.

In practice, crop growth can be limited by several factors during the growing season, while pests may occur any time. It may also not be economical to attempt to reach potential yields. A practical, action oriented distinction has been proposed by Rabbinge (1993). He distinguished (Figure 1):

- potential yield, with the same definition as De Wit's Production level 1. Weather variables, including $\mathrm{CO}_{2}$-level, and species characteristics are the yield defining factors. Modelling potential yield requires particularly the understanding of crop physiology and agrometeorology.

- attainable yield, roughly $50-20 \%$ below the potential yield; the reduction is caused by limiting factors such as water, nitrogen or phosphorus. Such limitations can largely be avoided by yield increasing measures (fertilizer, irrigation). Best farms attain this yield level. Soil physics and soil chemistry are important disciplines in the study of attainable yield, in additions to crop physiology and agrometeorology. 'Attainable yield' includes De Wit's production levels 2,3 and 4 .

- actual yield, roughly 50-0\% below the attainable yield due to reducing factors, such as weeds, pests and pollutants. Yield a reduction can be avoided by crop protection measures such as integrated pest management. This situation is very common in many of the worlds agricultural crops. 


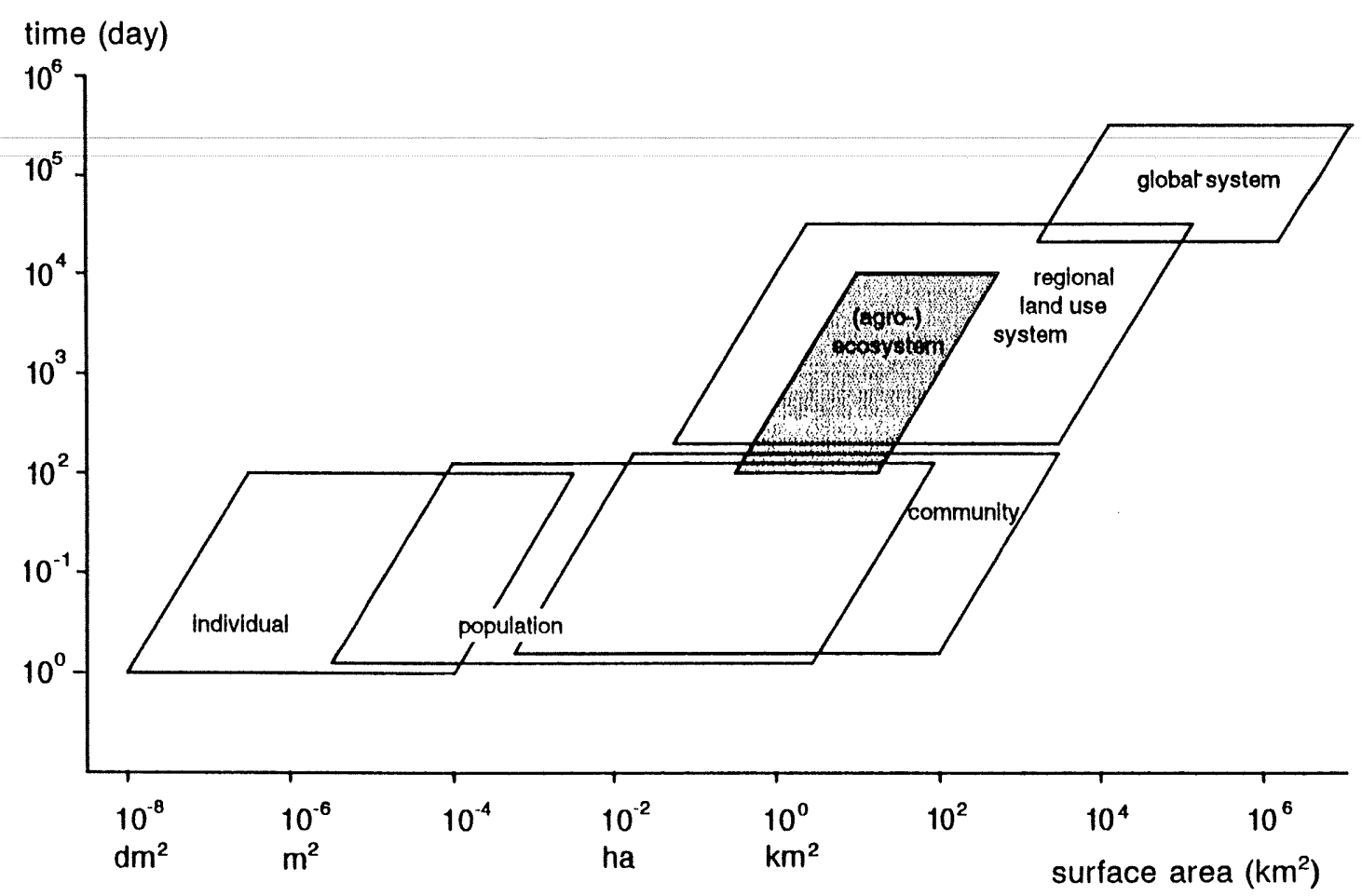

Figure 2. Temporal and spatial scales of units of analysis in production ecology. Source: Graduate School Production Ecology, Wageningen.

Systems of crop growth may also be categorised by hierarchical level. Typically at higher levels, the physical dimension ('size'), the time scale at which key processes react and progress (expressed as time coefficient), and the complexity of the system (expressed as the number of disciplines involved) increase. Figure 2 shows the scales commonly addressed in agricultural research. Important hierarchical levels are:

- the plot level: the system covers several square meters in surface area; processes have characteristic time coefficients of seconds to hours; many simulation studies address basic processes such as transport in soil or plants, interception, absorption of light and leaf photosynthesis; temporal changes of pests, etc.;

- the field level: the system covers around one hectare in surface area; processes have characteristic time coefficients of hours to days; studies address integration of basic processes to the field level; such as canopy photosynthesis, field evaporation, nutrient percolation, etc;

- the farm level: the system comprises several fields in one management unit, has a time horizon of several years and characteristic time coefficients of days to weeks; in addition to the processes at the field level, socio-economics is very important, as is management of machinery, stocks, personnel and cash;

- the regional level: the system comprises all land in a relatively uniform region of thousands of hectares, with time coefficients of months to years; socio-economics and limiting regional natural resources (e.g. water) are considered, possibilities and limitations are studies and mechanisms of change investigated. 


\section{Models}

A model is a schematic representation of the conception of a system. In the real world, the appearance of biological systems changes, and their models are often called 'dynamic'. The most obvious change in a crop production system is growth. Analysis of dynamic systems is based on the assumption that the state of the system at any particular time can be expressed quantitatively, and that changes in the system can be described in mathematical terms (De Wit and Goudriaan 1974). This leads to formulation of state-determined models in which state variables, driving variables, rate variables and auxiliary variables are distinguished. State variables characterise and quantify the current state of the system, such as the amount of biomass, the leaf surface area, the $\mathrm{N}$ content of a part of the system etc. Their values change according to rules based on the underlying physiological, physical and biochemical processes. Driving variables, such as meteorological variables, characterise the influence of the environment. The formulation of the relations between all variables is called the 'structure' of a model. The 'behaviour' of a model is the total of the changes in the numerical values of variables during simulation. For a more extensive discussion of systems analysis and modelling, see Penning de Vries et al. (1989), Leffelaar (1993), and Goudriaan and Van Laar (1994).

Simulation is the scientific activity of building and utilising explanatory models. Models are called 'explanatory' when their behaviour is based on process knowledge at a lower hierarchical level. This contrasts with demonstrative models, whose behaviour resembles that of the real system, but the rules that make it behave in that way are quite different. For example, images of a film may look like the real world, but are only a demonstrative model of it. Explanatory and demonstrative models come in many forms: dynamic mathematical models, scale models, graphical models, electric analogy models. Each form has particular advantages and disadvantages. We focus at explanatory dynamic mathematical models: such models are flexible, have most potential for application and for further development.

In the process of model development, one passes from a conceptual phase, through a model construction phase to evaluation and application. Skills, data requirements, and techniques used are different in these phases. Ten different steps can be distinguished in the process of model development (Table 1). Typically, modelers go many times back and forth between these steps, and not always even reach the end. Indeed, in a long process, completion of each step may be seen as a small milestone. The first phase, developing a conceptual model, is often the most difficult one.

\section{Uses of Models}

Automobiles can be very useful when the type of the car matches the task: busses for moving people, trucks for bulk transport, and Formula 1's for racing. The 
Table 1. Steps in systems research and model building. Source: Rabbinge and De Wit (1989)

\section{Conceptual phase \\ 1. formulation of objectives \\ 2. definition of system boundaries \\ 3. conceptualization of the system}

Comprehensive modelling phase

4. quantification of input relations

5. model construction

6. model verification

Evaluation and application phase

7. model validation

8. sensitivity analysis

9. simplification: summary models, decision rules

10. feasibility and scenario studies

same applies to models: they are useful only when the proper type is selected for a specific task.

Models can be useful for development of science, for prediction and for instruction, but not all at the same time. Scientifically interesting models are often too detailed for application, while models for predictive or management purposes are often too trivial or too crude to challenge scientific interest. Three 'values' can be attributed to models (Table 2):

Table 2. The relative values of certain uses of models in different phases of development. Source: Penning de Vries (1983)

\begin{tabular}{lllll}
\hline & $\begin{array}{l}\text { Predictive } \\
\text { value }\end{array}$ & $\begin{array}{l}\text { Scientific } \\
\text { value }\end{array}$ & $\begin{array}{l}\text { Instructive } \\
\text { value }\end{array}$ & Simplicity \\
\hline preliminary model & + & +++ & ++ & ++ \\
comprehensive model & ++ & +++ & + & + \\
summary model & +++ & + & +++ & ++ \\
\hline
\end{tabular}

- the scientific value of a model expresses the extend to which it helps us to understand the real world, to integrate the relevant processes of the system, to bridge disciplines and aggregation levels, to evaluate alternative hypotheses, and to suggest experiments to falsify them;

- the predictive value of a model expresses the degree in which it simulates accurately the behaviour of a system. It measures the usefulness of the model as an instrument for application of knowledge in practice and for planning, and for explorative feasibility studies. The less detailed the desired results are, the simpler the predictive model can be. Simulation for different scenario's of the environment, such as for climate change, is a popular form of investigating possible consequences;

- the instructive value of a model refers to its use for disseminating knowledge 
to graduate and post-graduate student, and to non-scientist end users such as extension services, farmers, policy makers. The model should convey the crucial behavioural aspects of an entire system in a transparent manner.

\section{Evaluation}

Evaluation is a broad term to describe the action of judging the value of a model. It comprises checking internal consistency and dimensions in computer programs, closed balances, comparison of model output with real world data, and judgement of practical utility. It is common experience that the behaviour of the model 'agrees' with that of experiments except for one of two aspects, which is 'corrected' by optimising the value of orfe or two parameters. This adjustment process, called calibration, should be avoided whenever possible, but is commonly used to tie simulation results to benchmark observations (e.g. Stol et al. 1992).

Evaluation of models remains often limited in depth as a result of too small a data base. Some models are only 'evaluated' by establishing a good correspondence between 'predicted' and 'observed' results, while the same observed results were used to derive constants in the model. This risks to reduce the explanatory nature of models. Strong experimentation is indispensable in parallel with modelling: experimentation at the explainable level for evaluation, and at the explanatory level for further improvement.

A source of concern is the brevity or inaccessibility of descriptions of many models and their programs. Too often, one is asked to believe an author without being able to check it. Some of the advantages of modelling are then lost. If documentation of a model is not rigorous, one must fear that also its evaluation was not thorough. There is a need for a standard of model quality.

\section{Examples of simulation}

\section{Models in research}

Explanatory simulation models are part and parcel of much of the quantitative research in agriculture and biology. Both preliminary and comprehensive models are common. The objective is to obtain a tool that explains the behaviour of the system. Generic models, such as SUCROS87 (Spitters et al. 1989), are often a starting point for their development. To account for specific processes (e.g. tillering in rice crops) or to target the models to specific objectives (e.g. understanding tuber formation dynamics in potato), research models are tailored to specific needs and circumstances. The procedure laid out in Table 1 applies very well to development of research models. Examples of such models are WHEAT for spring wheat (Van Keulen and Seligman 1987), and INTERCOM for crop-weed interactions (Kropff and Van Laar 1993). 
Table 3. Categories of pest damage. Sources: Rabbinge (1983), Boote et al. (1983)

\begin{tabular}{lll}
\hline Category & Process & Example \\
\hline assimilate sapper & tap assimilates & aphid \\
tissue consumer & removal tissue & insects \\
stand reducer & removal stem & stembore \\
photosynthetic rate reducer & damage chloroplast & diseases \\
leaf senecence accelerator & premature abcission & Cercospora \\
light stealer & shading & weeds \\
turgor reducer & modify water transfer & nematodes \\
\hline
\end{tabular}

Integration of disciplines leads to unifying principles. An example is the distinction of a limited number of categories of damage that the numerous species of insects and diseases can cause to crops, which is rooted in physiological mechanisms (Table 3).

Another example is the use of modelling for setting research priorities and for structuring of research activities. Simple models can already help to do so for broad conclusions, comprehensive models help to do so for specific hypotheses or knowledge gaps. For example, modelling identified the need for better knowledge of morphological development of crops and of maintenance respiration in order to make better predictive models (Spitters and Van Keulen 1990). However, these gaps have been found difficult to fill. In another case, use of models was more successful. Modelling studies hinted at the possibility that a sub-optimal $\mathrm{N}$-content of leaves after flowering was a cause of sub optimal production in rice (Penning de Vries et al. 1991; Kropff et al. 1993). Yet, this was unexpected, since exhaustive experimentation two decades earlier provided the bases of the common fertilisation regime. Improving the post flowering N-status indeed raised the yield level significantly (Kropff et al. 1993). The cause was traced to a modified soil environment, in which the originally optimal fertilising regime had become sub-optimal. Stimulated by this result, several modelling studies are now ongoing at the International Rice Research Institute (Penning de Vries et al. 1991), and much research is organised in programs in which modelling provides the backbone (Kropff et al. 1994).

A third example is the analysis of causes of variability and risk in winterwheat due to aphids (Rossing et al. 1994). Careful mathematical and statistical analysis of field and laboratory data showed that uncertainty about the initial aphid population contributed most to uncertainty about the threshold level for spraying. They conclude that better field observations are needed more than better models or other types of data.

\section{Models for instruction}

Simple models are needed for instruction, and summary models are better than preliminary models. In addition to the contents, it is desirable that the models are packaged in an attractive, user-friendly form. Few products are in this stage, 
probably because for scientists there is little stimulus to derive summary models and for programmers it is a major job of restricted commercial value.

Simulation models in the simulation language CSMP, with clear textbooks and exercises, are a good form of instructive models (e.g. De Wit and Goudriaan 1974; Penning de Vries et al. 1989). They have lead to a wealth of models for different subjects and objectives. CSMP has been abandoned by its author (IBM), but a compiler has been developed (Van Kraalingen et al. 1994) by which CSMP-style models can be used in a flexible FORTRAN Simulation Environment (Van Kraalingen 1993). A package for computer aided instruction in crop simulation is now commercially available.

\section{Models for prediction}

'Prediction' comes in many forms, including straightforward and real time prediction of final crop yield during a growing season (e.g. De Koning et al. 1993), exploration of consequences of 'what if' questions on management (e.g. Keating et al. 1993), exploration of the impact of climate change (e.g. Rosenzweig 1993), and evaluation of new 'designs' of crop ideotypes (e.g. Dingkuhn et al. 1993). Special attention should be given to the matching of model and objective, to availability of data, and to evaluation of some results.

An example of use of models for prediction is in quantitative land use evaluation. Such models need much geographical referenced data on soils, climate, and sometimes on land use. Typically, output (crop production) and input (water, chemicals) are computed per soil-climate unit for one or more crops and weather patterns; outputs are expressed on maps, as averages or probabilities. A good example is a simulation study for India (Figure 3). In this vast country, consistent guidelines are sought as to where production of wheat should be stimulated, about optimum sowing dates, and what quantity of irrigation water would be needed (Aggarwal 1993). In a follow up of that study, consequences of inaccuracies in basic data (or of their absence) were quantified (Aggarwal 1994), thereby identifying the soil parameters (and to a smaller extend the crop parameters) of which field measurement would add most to accuracy of production redictions. In this way, the study helps agricultural planners and guides research services.

Since variability is more difficult to measure than to simulate, models are indispensable to quantify variability at the crop, cropping system, and regional level (Penning de Vries 1994).

For deriving solid advice to decision makers, crop models still have a number of weaknesses. It is the responsibility of scientists to cure them. Weak spots are:

- poor quality control. There is insufficient quality control of models, particularly when applied in practice. As a result, results may be wrong or irreproducible, and models are sometimes difficult to transfer to others. There is a strong need for guidelines for description (including range of validity), evaluation, documentation (scientific, technical), maintenance and distribution. 


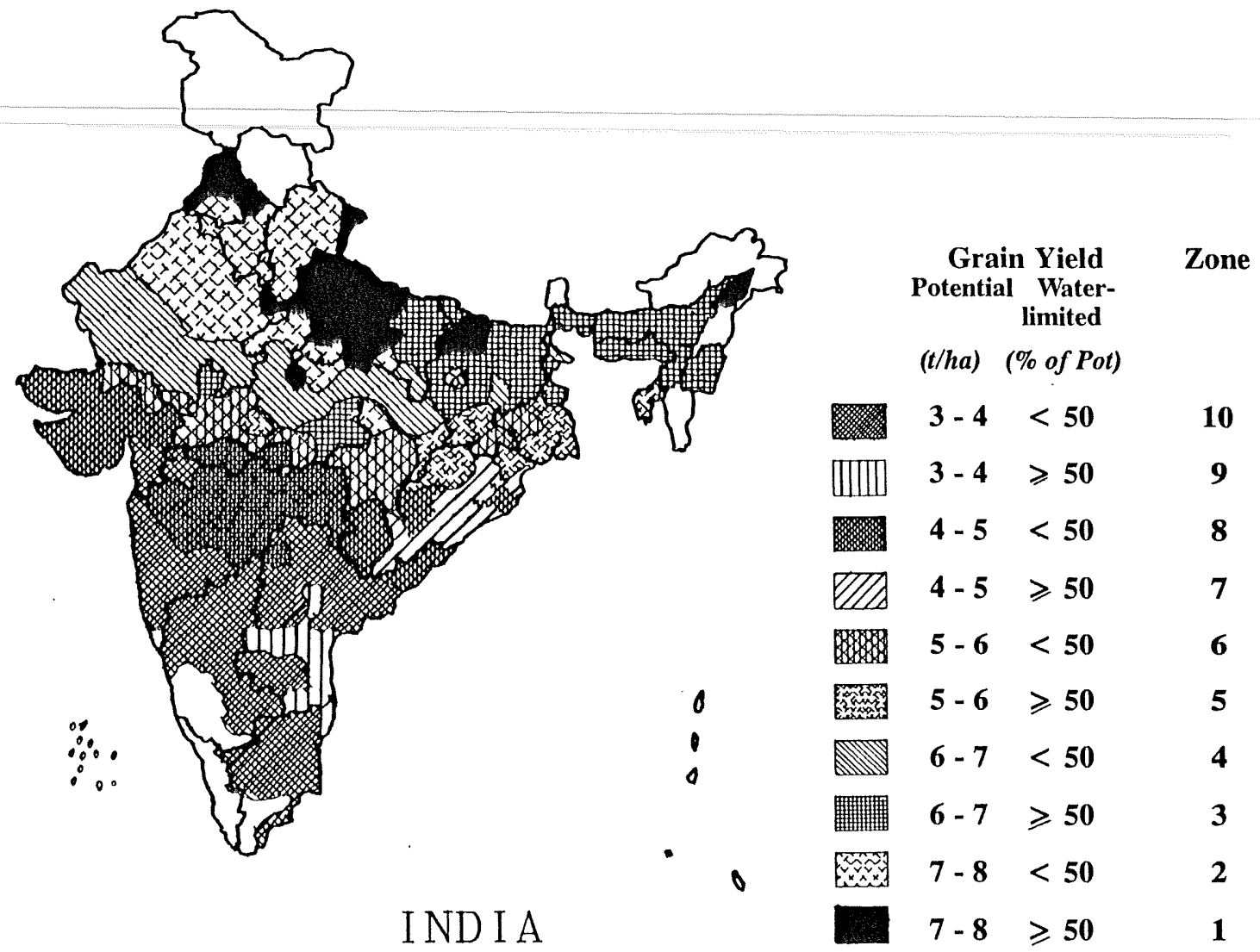

Figure 3. Iso-yield wheat zones of India based on potential and water limted productivity. Blank areas were not simulated. Source: Aggarwal (1993).

- unknown accuracy. Consequences of inaccuracies in basic inputs and uncertainties in model structure are not always determined, so that the precision of simulation results is unknown.

- oversimplification. Crop plants, pest populations and soils are not homogeneously distributed in space. Yet, this is rarely taken into account at plot, field or regional level. The consequences need investigation. Oversimplification of weather data (by averaging) was shown to cause significant deviations in simulated yields (Nonhebel 1993).

\section{Future crop modelling}

\section{Geographic Information Systems}

There is a large demand for predictions with models in a spatial context: for agro-ecological zoning (Aggarwal 1994), to quantify impacts of climate change, for regional yield prediction (De Koning et al. 1993) and land use feasibility and scenario studies (WRR 1992). The combination of GIS, that stores spatially distributed soil characteristics, data bases with weather data, and crop models is very powerful. Depending on the purpose, the basic soil, crop and weather 
data are observed values when explanation is sought, or hypothetical ones when new opportunities are sought. GIS-model combinations are ideal for exploring possibilities for land use, and for planning.

Yet, a warning is necessary:

- basic data in right formats are generally in short supply. Large scale studies generally must work with many approximate data. For weather data, large historic data sets of daily weather are scarce, and sometimes only commercially available. For soils data, international standardisation is an issue, and only few pedotransfer functions have been made (Bouma et al. 1993). A major quantitative and world-wide soil data base (SOTER: Oldeman 1994) will therefore not soon be available. For crop species and varieties, small data bases exist, but are scattered. The largest collections are for crop models of the Decision Support System for Agrotechnology Transfer (Uehara and Tsuji 1993) and for WOFOST (Boons et al. 1993).

- aggregation of simulation results at a plot or field level to the regional level has still unresolved questions, like how to deal with temporally and spatially varying inputs (e.g. sowing date across a region) and with uncertainty (Bouman et al. 1993), and how to deal with feed back between fields (e.g. pest populations, water storage).

- evaluation of simulated results is generally not possible in the traditional way (comparing simulated results with experimental data) simply because such experiments cannot be done and observations may be inadequate. E.g. in a recent study to predict regional crop yields for the Netherlands, we planned to compare simulated national crop yields with official statistics. Yet, we learned that official statistics are based on visual estimates, and have a relative uncertainty as large as that of the best simulations (around 5\%, De Koning et al. 1993). In addition to testing as many model components as possible, new ways of evaluation ecoregional models must be developed. This is a necessity, because simulation without evaluation goes astray.

\section{Multiple goal linear programming}

Farms produce food and income to farmers, but can also cause air and ground water pollution, and provide employment. These intended and unintended 'outputs' can be seen as goal variables. The degree in which crop production contributes to these goals can be quantified in technical coefficients. Alternative cropping systems and farm management practices realise these goals to different degrees; technical coefficients link quantitatively every practice considered to every goal variable.

The actors involved (farmers, regional boards, governments) want to maximise/minimise these goals, but as these are often in conflict, a compromise must be sought. Modelling can provide such an instrument 'to help in negotiation' (R. Brinkman, FAO, pers. comm.). In recent years, a technique (called multiple goal linear programming) has been developed (De Wit et al. 1988) in which the production system can be optimised and the exchanges values 


\section{LAND USE}

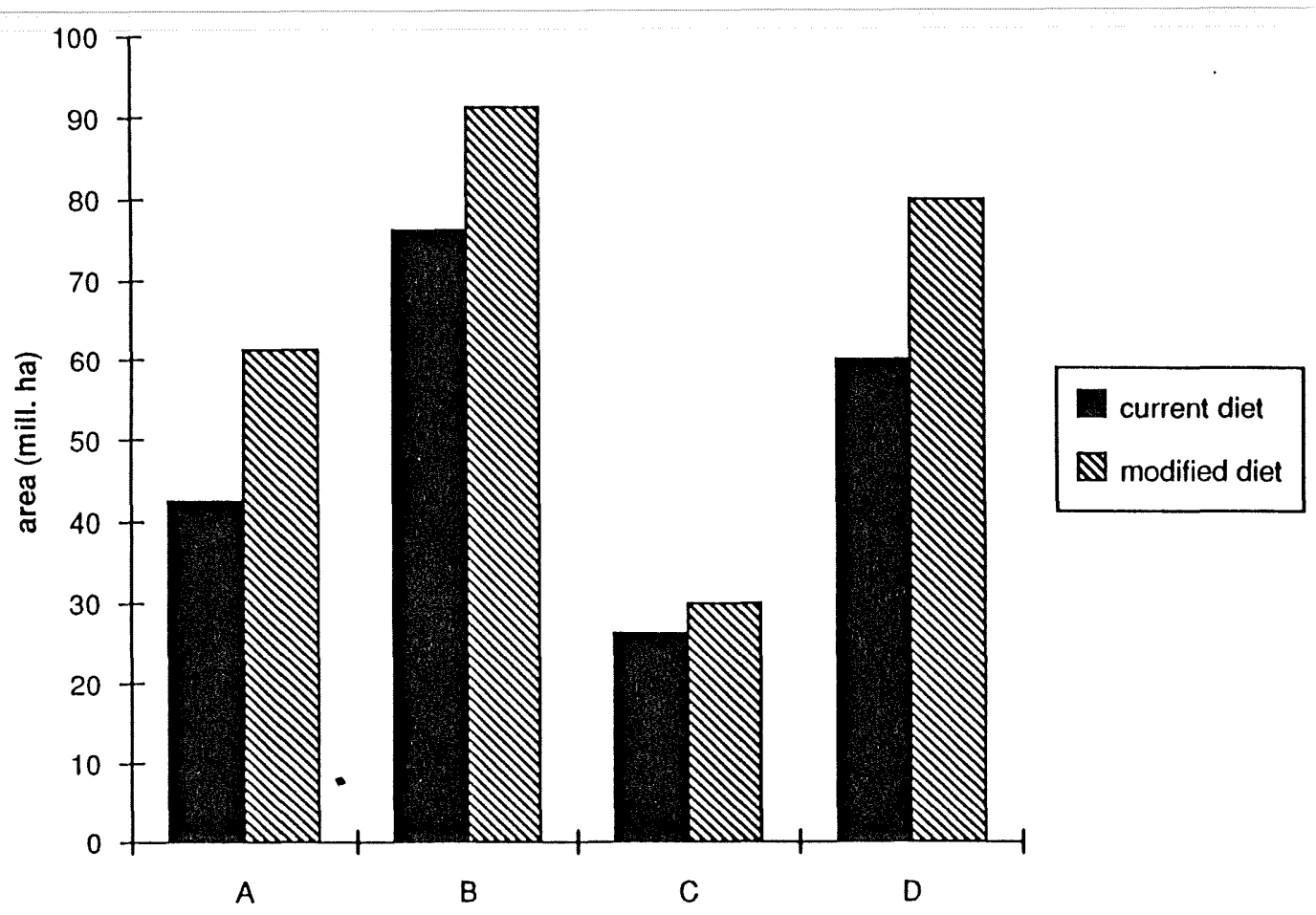

Figure 4. Differences in land use between four scenarios: A: free trade, B: regional development, C: nature and landscape, D: environmental protection. Source: WRR (1992).

can be determined between goal variables. With this technique, one can select from very many possible cropping systems and management practices the one that produces the best mix of a high income, low ground water pollution and little effort. Very important is that this technique necessitates collaboration with socio-economic sciences. In a large study at a regional scale, options for future agriculture and land use were quantified for many regions of the $12 \mathrm{EC}$ countries (WRR 1992). Optimisation towards main objectives of key actors in European agriculture showed how large the window is for policy making (Figure 4). Such modelling studies can help policy makers in tactical and strategic decisions.

This optimisation technique typically requires a large number of technical coefficients. Crop simulation will often be used to provide such data, as trials are expensive and time consuming. For instance Veeneklaas et al. (1990) investigated possibilities for future land use in a poor region in central Mali. Simulation models provided yields of millet, sorghum and range lands for areas that were inaccessible and for situations that could not be tested in trials (e.g. fertilisation). Expert judgement proved the behaviour of these models acceptable. Clearly, this land use planning study could not have occurred without crop models.

In another attempt, however, it appeared impossible to provide technical 

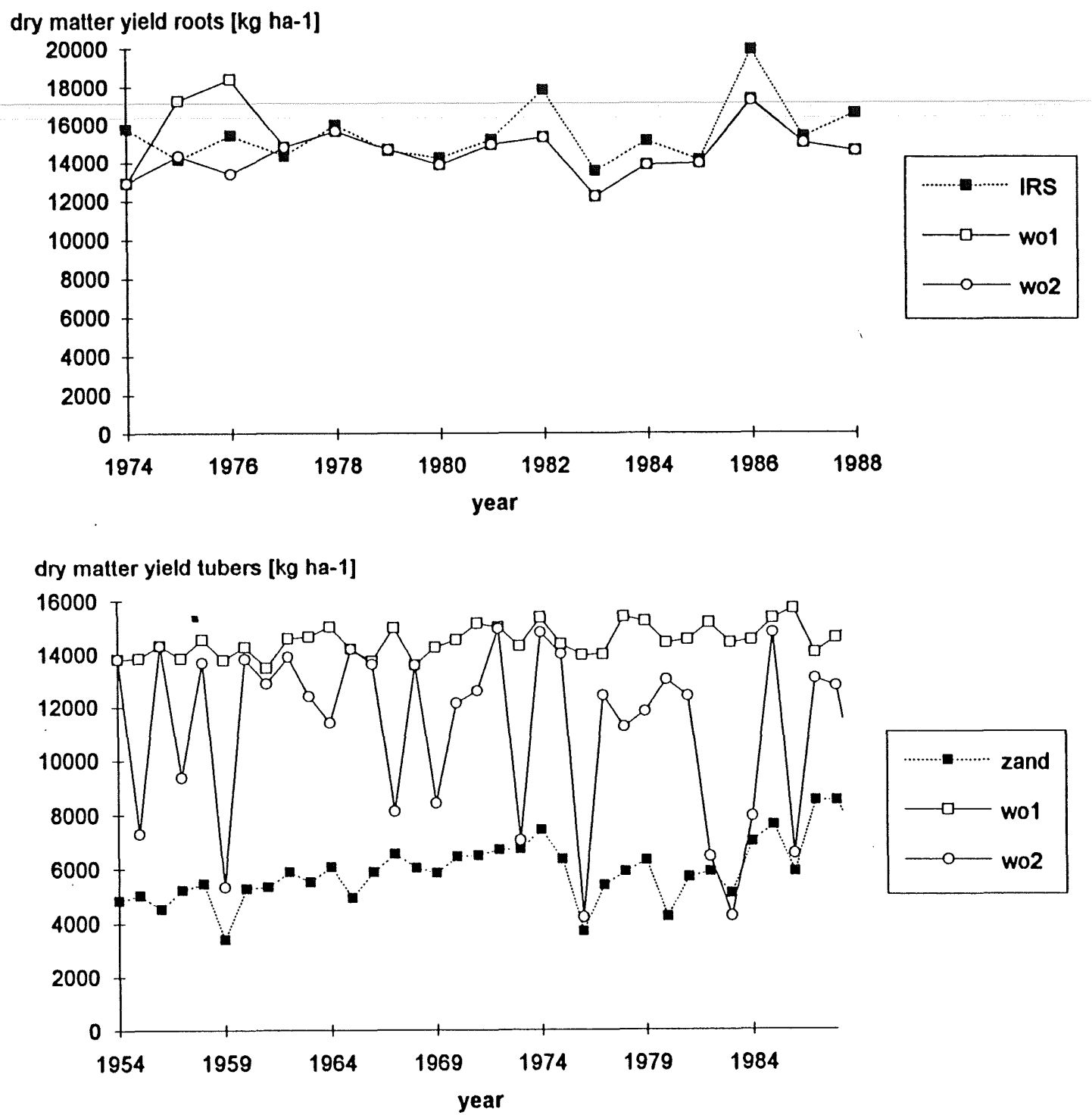

Figure 5. Experimental yields (black), simulated potential production (open squares) and simulated water limited production (open circles) of sugar beet roots (a) and potato tuber (b). Source: Habekotté (1994).

coefficients by modelling. In this case, a study for farms in the Netherlands, a coefficient was required for yield variability as function of crop and management. The generic model used did produce reasonable values for yield variability of some crops but not for others (Figure 5). This may be due to inaccuracy in the model (as not all crop and soil parameters were measured on the spot), but also because 'observed yields' have a significant inaccuracy. However, as variability was already approximately known and simulation could not improve its quality or provide extra data, this optimisation study is carried out with coefficients from field trials and expert judgement only (Schans and Habekotté 1995).

Though a very potent technique, we should not overlook the limitations. These are partially the same as we saw previously: lack of basic data, lack of 
data for evaluation of optimisation results. A specific limitation is that there is no procedure yet to translate uncertainty in basic data into uncertainty in end results. Particularly when crop models, GIS and LP are used all together, a number of the mentioned limitation apply simultaneously, and margins of error might well exceed $100 \%$.

\section{Remote Sensing}

Yet another development is that crop models are used to interpret data collected by Remote Sensing. Certain ratios of specific wave lengths, per pixel, can be interpreted in terms of leaf area and canopy structure. Such values can serve to monitor the status of the crop in a region, or as inputs for a crop model to predict the end of season yield (Bouman 1992). In the near future, Remote Sensing will help to detect what crops grow where, provide data on the area under specific crops, and provide estimates of 'initial biomass' for growth simulation (Vossen, ISPRA, pers. comm.).

\section{Userfriendliness}

Over the past decade, some models have grown much in size, most grew in complexity. This can make them almost impossible to transport to other computer systems and other users. To ease such problems, 'shells' are introduced that reduce the need for technical expertise of the user and enable transportability. The IBSNAT project (Uehara and Tsuji 1993) has been among the first to develop a shell around its crop simulation models, called a Decision Support System for Agrotechnology Transfer (DSSAT), of which version 3.0 has been released. It provides a user-friendly environment to select models, to select sets of soil, crop and weather data, to specify crop management techniques, and to carry out simulations. DSSAT is widely used (Tsuji and Balas 1993). The Agricultural Production system Simulator (APSIM, McCown et al. 1995) is a modern shell, nearing completion. It contains several crop and soil models, whose structure is geared to cropping systems research. The models are accessible to users. For a group of models for rice based cropping systems, a first version of the 'SARP-shell' has been released (by the project 'Simulation and systems Analysis for Rice Production', Ten Berge 1993). In addition to easy selection of alternative crop and soil modules and corresponding data, users are free to modify all data and models, switching is possible between simulation of state variables or enforcing their values, and uncertainty analysis has been made easy.

Shells provide also interfaces with an increasing number of tools for inputs and outputs: weather data generation, GIS, statistical tools, uncertainty analysis, add-ons for economic analyses, etc. Much expansion is expected. 


\section{Training}

One of the bottlenecks for applying models is the low number of skilled modelers. This is not solved by more user-friendly programs. For running a model, a limited amount of technical skill is needed, and this even decreases with the advent of more user-friendly models, data bases, and other software. However, effective use of these tools requires scientists trained to select the model best suited for the objectives, to recognise when sets of basic data are appropriate and complete, and to interpret often complex results. We conclude that while user-friendly tools bring modelling into the hands of more scientists, also more skilled modelers are needed to guide and help users. The Graduate School Production Ecology is one of the few locations where such training is provided. Another location is the Asian Institute of Technology. Particularly developing countries have to too few training centres. SARP (Penning de Vries et al. 1988) and IBSNAT (Uehara and Tsuji 1993) have been effective in training, but their courses still need institutionalisation (Singh et al. 1994). That is why concerted actions among various groups are being initiated.

Most development in modelling occurs in multidisciplinary groups of scientists of 4-6 scientists (cf. Penning de Vries 1983). Indeed, successful building of crop production models requires a 'critical mass' of at least 4-6 scientists from different but related disciplines, who collaborate closely for a long period. This concept was confirmed in a recent training and research project in Asia, where more than 18 modelling teams were formed and proved to be productive (Ten Berge 1993).

\section{References}

Aggarwal P K (1993) Agroecological zoning using crop growth simulation models: characterization of wheat environments of India. Pages 97-109 in Penning de Vries F W T, Teng P S, Metselaar K (Eds.) Systems Approaches for Sustainable Agriculture. Kluwer Academic Publishers, Dordrecht, Netherlands.

Aggarwal P K (1994) Uncertainties in plant, soil and weather inputs used in crop growth models: implications for simulated outputs and their applications. Agricultural Systems (in press).

Bastiaans L (1993) Understanding Yield Reduction in Rice Due to Leaf Blast. Ph.D. Thesis, Wageningen Agricultural University, Wageningen, The Netherlands.

Boons E R, De Koning G H J, Van Diepen C A, Penning de Vries F W T (1993) Crop-Specific Simulation Parameters for Yield Forecasting Across the European Community. Simulation Report CABO-TT 32, CABO, Wageningen, The Netherlands.

Boote, K J, Jones J W, Mishoe J W, Berger R D (1983) Coupling pests to crop growth simulators to predict yield reductions. Phytopathology 73:1581-1587.

Bouma, J, Wopereis M C S, Wösten J H M, Stein A (1993) Soil data for crop-soil models. Pages 207 -220 in Penning de Vries F W T, Teng P S, Metselaar K (Eds.) Systems Approaches for Sustainable Agriculture. Kluwer Academic Publishers, Dordrecht, The Netherlands.

Bouman, B A M (1992) Linking physical remote sensing models with crop growth simulation models, applied for sugar beet. Int. J. Remote Sensing 13(14):2565-2581.

Bouman B A M, Jansen M J W (1993) RIGAUS. Random Input Generator for the Analysis of 
Uncertainty in Simulation. Simulation Reports CABO-TT 34. CABO-DLO, Wageningen, The Netherlands.

De Wit C T, Goudriaan J (1974) Simulation of Ecological Processes. Simulation Monographs. PUDOC, Wageningen, The Netherlands.

De Wit C T, Penning de Vries F W T (1982) Pages 23-27 in La Productivité des Pâturages Sahéliens. Agricultural Research Report 918. PUDOC, Wageningen, The Netherlands.

De Wit C T, Van Keulen H, Seligman N G, Spharim I (1988) Application of interactive multiple goal programming techniques for analysis and planning of regional agricultural development. Agricultural Systems 26(3):211-230.

Dingkuhn M, Penning de Vries F W T, Miezan K M (1993) Improvement of rice plant type concepts: systems research enables interaction of physiology and breedings. Pages 19-36 in Penning de Vries F W T, Teng P S, Metselaar K (Eds.) Systems Approaches for Sustainable Agriculture. Kluwer Academic Publishers, Dordrecht, The Netherlands.

Goudriaan, J, Van Laar H H (1994) Modelling Potential Crop Growth Processes. Textbook with Exercises. Current Issues in Production Ecology, Vol. 2. Kluwer Academic Publishers, Dordrecht, The Netherlands.

Habekotté B (1994) Evaluatie van een Gewasgroeimodel voor Opbrengstberekening van Verschillende Gewassen. Simulation Reports CABO-TT 36 (24 pp). AB-DLO, P.O. Box 14, 6700 AA Wageningen, The Netherlands.

Keating B A, McCown R L, Wafula B M (1993) Adjustment of nitrogen inputs in response to a seasonal forecats in a region of high climatic risk. Pages 233-252 in Penning de Vries F W T, Teng P S, Metselaar K (Eds.) Systems Approaches for Sustainable Agriculture. Kluwer Academic Publishers, Dordrecht, The Netherlands.

Koning G H J, Jansen M J W, Boons-Prins E R, Van Diepen C A, Penning de Vries F W T (1993) Crop Growth Simulation and Statistical Validation for Regional Yield Forecasting Across the European Community. Simulation Report CABO-TT 31. CABO-DLO, Wageningen, The Netherlands.

Kropff M J, Van Laar H H (Eds.) (1993) Modelling Crop-Weed Interactions. CAB-international, Wallingford, UK.

Kropff M J, Cassman K G, Penning de Vries F W T, Van Laar H H (1993) Increasing the yield plateau in rice and the role of global climate change. J. Agric. Met. 48(5):795-798.

Kropff M J, Penning de Vries F W T, Teng P S (1994) Capacity building and human resource development for applying systems analysis in rice research. Pages 323-340 in Goldsworthy P, Penning de Vries F W T (Eds.) Opportunities, Use and Transer of Systems Research Methods in Agriculture to Developing Countries. Kluwer Academic Publishers, Dordrecht, The Netherlands.

Leffelaar P A (Ed.) (1993) On Systems Analysis and Simulation of Ecological Processes. Current Issues in Production Ecology, Vol. 1. Kluwer Academic Publishers, Dordrecht, The Netherlands.

McCown, R L, Hammer G L, Hargreaves J N G, Holzworth D P, Freebairn D M (1995) APSIM, a novel software system for model development, model testing, and simulation in agricultural systems research. Agric. Systems (in press).

Nonhebel S (1993) The Importance of Weather Data in Crop Growth Simulation Models and Assessment of Climate Change Effects. Ph.D. Thesis, Agricultural University, Wageningen, The Netherlands.

Oldeman L R (1994) Issues of development and management of databases. Pages 167-178 in Goldsworthy P, Penning de Vries F W T (Eds.) Oportunities, Use and Transer of Systems Research Methods in Agriculture to Developing Countries. Kluwer Academic Publishers, Dordrecht, The Netherlands.

Penning de Vries F W T (1983) Modelling of growth and production. Pages 118-150 in Lange O L, Nobel P S, Osmond C B, Ziegler H (Eds.) New Encyclopedia of Plant Physiology, New Series. Springer-Verlag, Berlin, Germany.

Penning de Vries F W T, Rabbinge R, Jansen D M, Bakema A (1988) Transfer of systems analysis and simulation in agriculture to developing countries. Agricultural Administration and Extension 29:85-96. 
Penning de Vries F W T, Jansen D M, Ten Berge H F M, Bakema A H (1989) Ecophysiological Processes in Several Annual Crops. Simulation Monograph 29, PUDOC, Wageningen, The Netherlands and IRRI, Los Banos, Philippines.

Penning de Vries F W T, Kropff M J, Teng P S, Kirk G J D (Eds.) (1991) Systems Simulation at IRRI. IRRI Research Paper Series, 151, Los Banos, Philippines.

Penning de Vries F W T (1994) Computers, climate and risk. Pages 27-32 in Fifth International Congress for Computer Technology in Agriculture. Enabling Technologies for Land Use and Resource Management. Royal Agricultural Society of England, Warwickshire, UK.

Rabbinge R (1983) How to use combination models in crop protection? Pages 31-45 in Jeger M J (Ed.) The Development of Models for Practical Crop Protection. Bulletin IOBL/WPRS New Series VI, 2.

Rabbinge R (1993) The ecological background of food production. Pages 2-29 in Crop Protection and Sustainable Agriculture. CIBA Foundation Symposium, August 22-25. (Ed.) Crop Protection and Sustainable Agriculture. John Wiley \& Sons, New York, USA.

Rabbinge R, De Wit C T (1989) Systems, models and simulation. Pages 3-15 in Rabbinge R, Ward S A, Van Laar H H (Eds.) Simulation and Systems Management in Crop Protection. Pudoc, Wageningen, The Netherlands.

Rosenzweig C (1993) Recent global assessments of crop responses to climate change. International Crop Science 1:265-272.

Rossing W A H, Daamen R A, Jansen M J W (1994) Undertainty analysis applied to supervised control of aphids and brown rust in winter wheat. II. Relative importance of different components of uncertainty. Agricultural Systems, 44:449-460.

Schans J, Habekotté B (1995) Optimization of cropping systems at the farm level (in prep.).

Singh G, Pathak B K, Penning de Vries F W T (1994) Requirements for systems research in agricultural and environmental sciences. Pages 255-266 in Goldsworthy P, Penning de Vries $F$ W T (Eds.) Opportunities, Use and Transer of Systems Research Methods in Agriculture to Developing Countries. Kluwer Academic Publishers, Dordrecht, The Netherlands.

Spitters C J T, Van Keulen H, Van Kraalingen D W G (1989) Pages 147-177 in Rabbinge R, Ward S A, Yan Laar H H (Eds.) Simulation and Systems Management in Crop Protection. PUDOC, Wageningen, The Netherlands.

Spitters C J T, Van Keulen H (1990) Toepassing van Simulatie en Systeemanalyse: Stand van Zaken en Knelpunten. CABO-Verslag 128, Centrum Agrobiologisch Onderzoek, Wageningen, The Netherlands.

Stol W, Rouse D I, Van Kraalingen D W G, Klepper O (1992) FSEOPT, a FORTRAN Program for Calibration and Uncertainty Analysis of Simulation Models. Simulation Report CABO-TT 24. CABO-DLO, Wageningen, The Netherlands.

Ten Berge H F M (1993) Building capacity for systems research at national agricultural research centres: SARP's experience. Pages 515-538 in Penning de Vries F W T, Teng P S, Metselaar K (Eds.) Systems Approaches for Sustainable Agriculture. Kluwer Academic Publishers, Dordrecht, The Netherlands.

Tsuji G Y, Balas S (1993) The IBSNAT Decade. Dept. Agronomy and Soil Science, College of Tropical Agriculture and Human Resources, University Hawaii, Honolulu, USA.

Uehara G, Tsuji G Y (1993) The IBSNAT project. Pages 505-514 in Penning de Vries F W T, Teng P S, Metselaar K (Eds.) Systems Approaches for Sustainable Agriculture. Kluwer Academic Publishers, Dordrecht, The Netherlands.

Van Keulen H, Seligman N G (1987) Simulation of Water Use, Nitrogen Nutrition and Growth of a Spring Wheat Crop. Simulation Monographs, PUDOC, Wageningen, The Netherlands.

Van Kraalingen, D W G (1993) The FSE System for Crop Simulation, Version 2.0. CABO-TPE Simulation Report 23. CABO-DLO, Wageningen, The Netherlands.

Van Kraalingen D W G, Rappoldt C, Van Laar H H (1994) The FORTRAN Simulation Translator (FST), a simulation language. In Goudriaan J, Van Laar H H (Eds.) Simulation of Crop Growth Processes. Kluwer Academic Publishers, Dordrecht, The Netherlands (in press).

Veeneklaas F R, Cissé S, Gosseye P A, Van Duivenbooden N, Van Keulen H (1990) Competition 


\section{F.W.T. Penning de Vries and R. Rabbinge}

for Limited Resources (Vol. 4). Centre for Agrobiological Research, P.O. Box 14, Wageningen, The Netherlands.

WRR (1992) Ground for Choices, four perspectives for the rural areas in the European Community. Netherlands Scientific Council for Government Policy, SDU-Publisher, The Hague, The Netherlands. 